
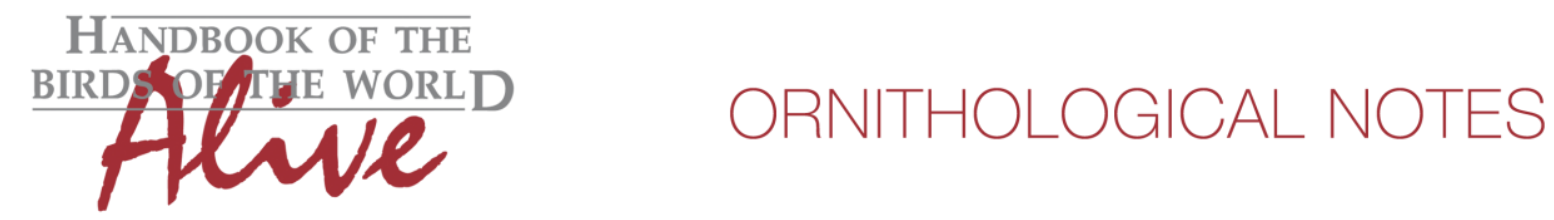

\title{
Notes on the vocalizations of Brewer's Sparrow (Spizella breweri)
}

Peter Boesman

In the following we briefly analyze and compare voice of the two races of Brewer's Sparrow (Spizella breweri). We also try to quantify the extent of any vocal differences using the criteria proposed by Tobias et al. (2010), as a support for taxonomic review. We have made use of sound recordings available on-line from Xeno Canto (XC).

Song of both races is structurally similar.

Vocal differences have already been documented and discussed (Spencer 2014), from where the following extract:

The full song of breweri typically sounds very buzzy throughout, descending from very highpitched, insect-like buzzes to lower pitched buzzes, but rarely having anything that one would describe as "musical" about them. This is due to the broadband nature of all of the elements of the song. Most phrases in the long song are made up of two alternating notes that comprise the buzz, and in nominate breweri both of these elements are broadband, or if one is less so then the broadband one dominates.

The full song of taverneri, on the other hand, gives a much less buzzy impression. The overall structure of the song is the same - it typically starts out with very high-pitched, insect-like phrases that quickly descend into the variable series of trills. The difference comes in the fact that elements of the majority of the phrases in the song are noticeably less broadband than in breweri, so that they sound more musical and tinkling. This difference isn't huge, and there is considerable variation, so it is important to listen to enough of the song to get a general impression rather than make the call on just one or two elements.

There is however some uncertainty about atypical Colorado highland birds, a case which remains unresolved.

Some examples:

nominate

simple song
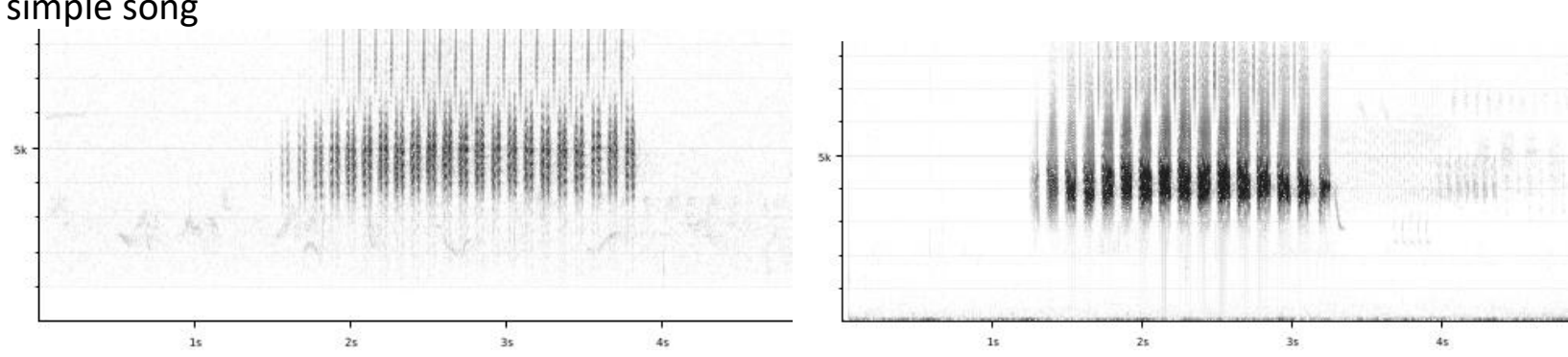
HANDBOOK OF THE

BIRDS PF/THE WORLD

Alive

full song

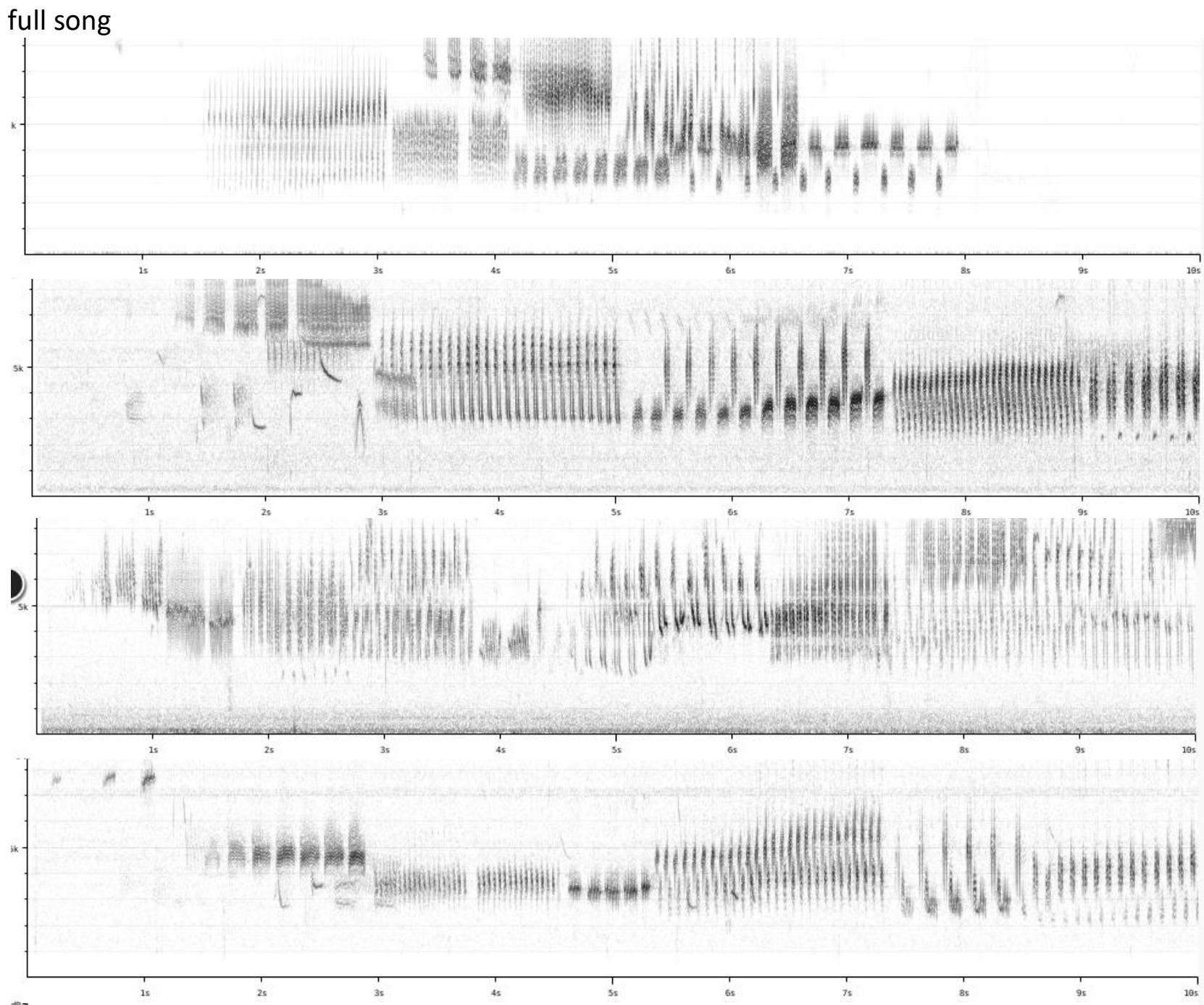

taverner

simple song

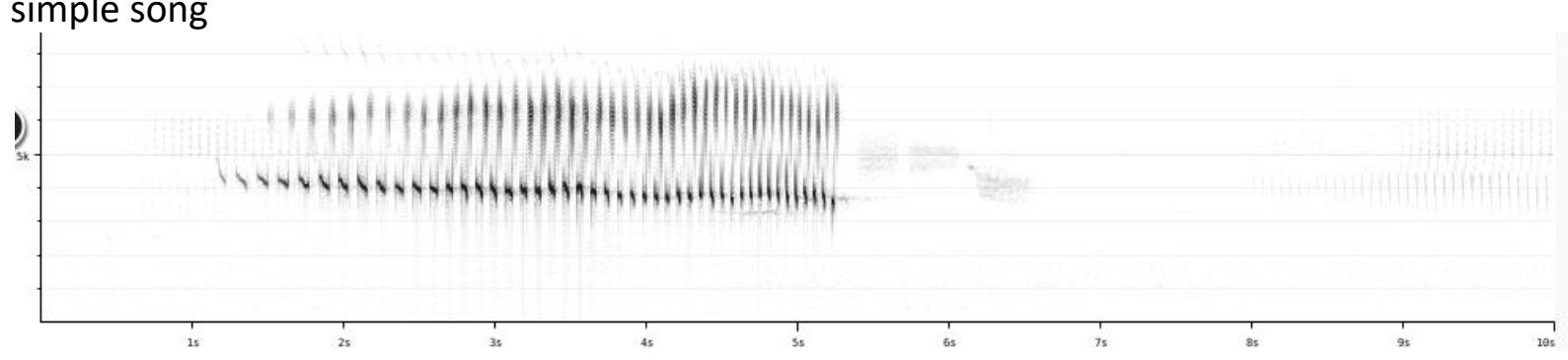

full song

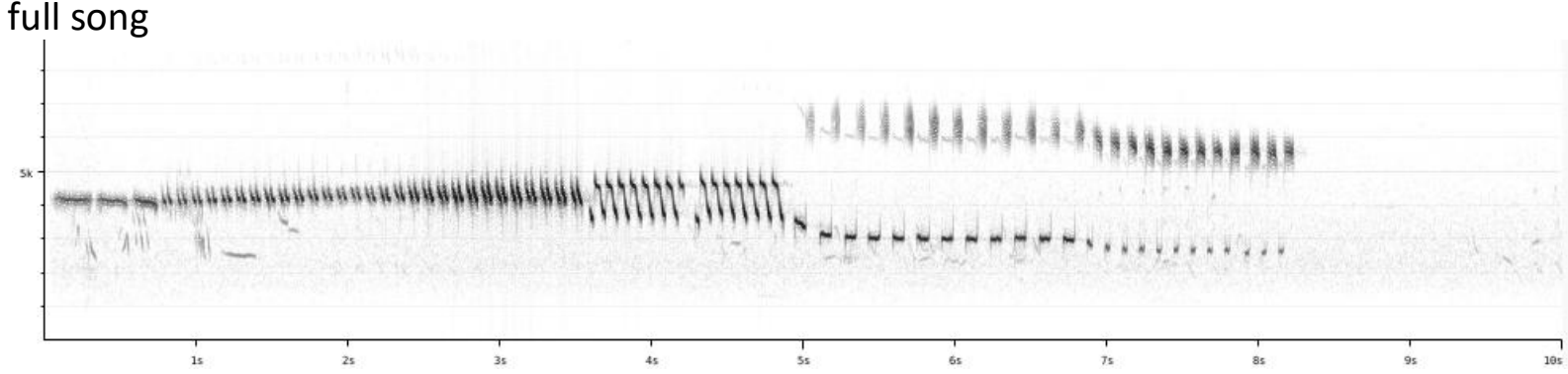



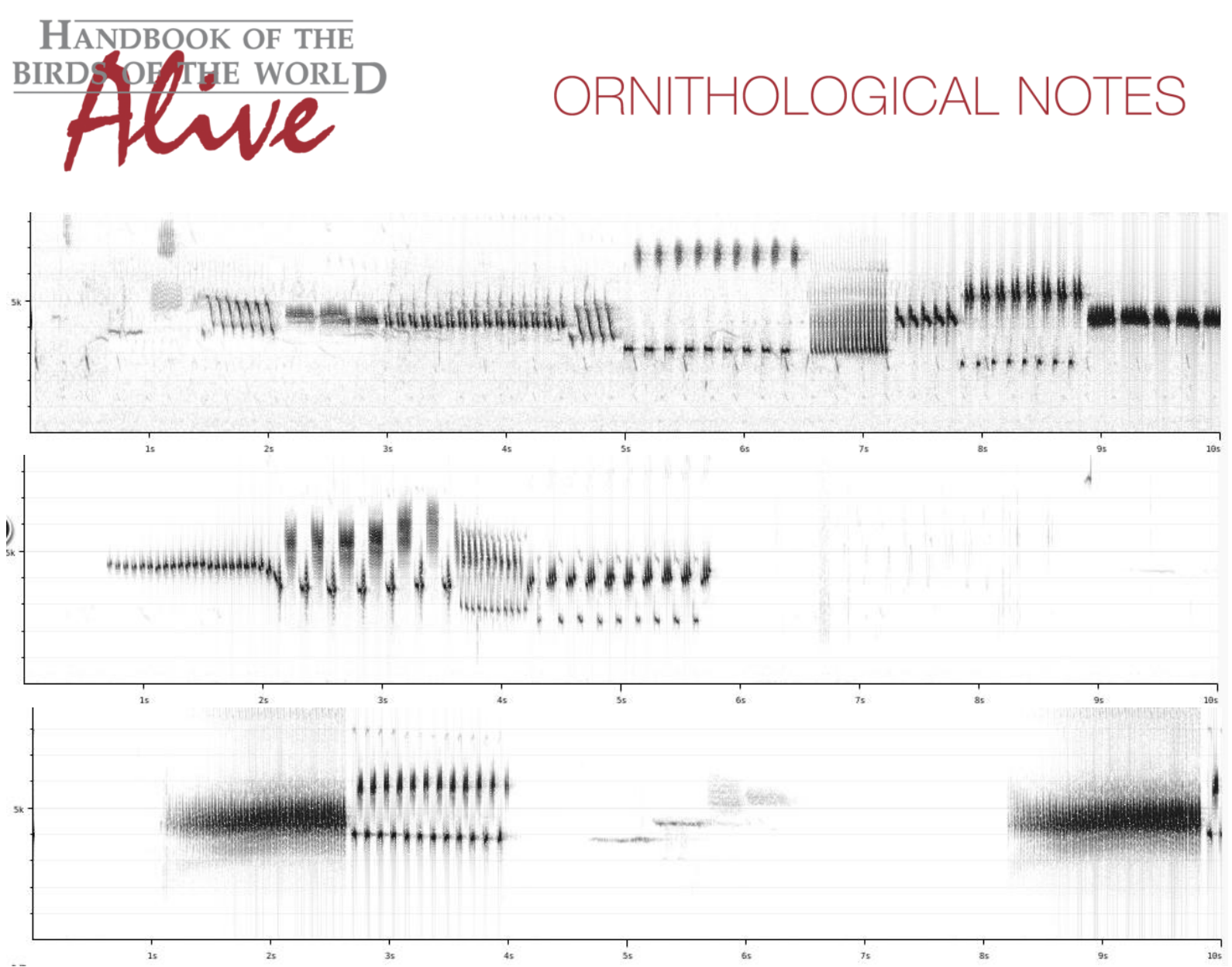

These examples illustrate quite well the difference in bandwidth of individual notes between both races.

All in all, it would seem that based on 'average frequency range (bandwidth) of notes' or 'number of notes in a song phrase with bandwidth less than $1 \mathrm{kHz}$ ', one can categorize the majority of full songs, with taverni having notes with a much narrower freq. range (score 2).

This note was finalized on 24th May 2016, using sound recordings available on-line at that moment. We would like to thank the many sound recordists who placed their recordings for this species on XC, in particular Andrew Spencer and Richard Webster for their extensive sound collections.

\section{References}

Spencer, A. (2014). How to identify a Timberline Sparrow. http://earbirding.com/blog/archives/4764

Tobias, J.A., Seddon, N., Spottiswoode, C.N., Pilgrim, J.D., Fishpool, L.D.C. \& Collar, N.J. (2010). Quantitative criteria for species delimitation. Ibis 152(4): 724-746. 


\section{Recommended citation}

Boesman, P. (2016). Notes on the vocalizations of Brewer's Sparrow (Spizella breweri). HBW Alive Ornithological Note 357. In: Handbook of the Birds of the World Alive. Lynx Edicions, Barcelona. (retrieved from http://www.hbw.com/node/1252899 on 28 October 2016). 